\title{
Imaging of Prostate Cancer with Immuno-PET and Immuno-SPECT Using a Radiolabeled Anti-EGP-1 Monoclonal Antibody
}

\author{
Catharina M. van Rij ${ }^{1,2}$, Robert M. Sharkey ${ }^{3}$, David M. Goldenberg ${ }^{3}$, Cathelijne Frielink ${ }^{1}$, Janneke D.M. Molkenboer ${ }^{1}$, \\ Gerben M. Franssen ${ }^{1}$, Wietske M. van Weerden ${ }^{4}$, Wim J.G. Oyen ${ }^{1}$, and Otto C. Boerman ${ }^{1}$ \\ ${ }^{1}$ Department of Nuclear Medicine, Radboud University Nijmegen Medical Center, Nijmegen, The Netherlands; ${ }^{2}$ Department of \\ Pharmacy, Radboud University Nijmegen Medical Center, Nijmegen, The Netherlands; ${ }^{3}$ Garden State Cancer Center, Center for \\ Molecular Medicine and Immunology, Morris Plains, New Jersey; and ${ }^{4}$ Department of Urology, Erasmus Medical Center, Rotterdam, \\ The Netherlands
}

hRS7 is a humanized IgG1 monoclonal antibody directed against the epithelial glycoprotein-1 (EGP-1; also known as TROP2). This antigen is found in many epithelial cancers, including prostate cancer, and therefore this antibody could be suitable for targeting this cancer. In this study, the characteristics of hRS7 for targeting prostate cancer were examined. The potential for immuno-PET with ${ }^{89} \mathrm{Zr}$-hRS7 and immuno-SPECT with ${ }^{111} \mathrm{In}$-hRS7 was assessed using nude mice with human prostate cancer xenografts. Methods: EGP-1 expression was assessed by immunohistology in human primary and metastatic prostate cancer samples and in PC3 xenografts. The optimal antibody protein dose for prostate cancer targeting was examined in nude mice with subcutaneous PC3 xenografts, and then the biodistribution of ${ }^{111} \mathrm{In}-,{ }^{125} \mathrm{I}$, and ${ }^{89} \mathrm{Zr}$-labeled hRS7 was determined in subcutaneous PC3 xenografts at 1,3 , and $7 \mathrm{~d}$ after injection. Immuno-PET and immuno-SPECT were performed with ${ }^{89} \mathrm{Zr}$-hRS7 and ${ }^{111} \mathrm{In}$-hRS7 in mice with subcutaneous and intraprostatic PC3 xenografts, respectively. Results: Immunohistochemical analysis showed abundant EGP-1 expression in human primary and metastatic prostate cancers and in PC3 xenografts. ${ }^{111} \mathrm{In}-\mathrm{hRS} 7$ and ${ }^{89} \mathrm{Zr}$-hRS7 preferentially and specifically accumulated in PC3 xenografts, with tumor uptake as high as $60 \%$ injected dose per gram at a protein dose of $0.1 \mu \mathrm{g}$ per mouse. PC3 tumors in nude mice were clearly visualized with both tracers with immuno-PET and immunoSPECT. Conclusion: hRS7 shows excellent in vivo tumor targeting in human prostate cancer xenografts. Therefore, hRS7 is a potential vehicle for targeting prostate cancer.

Key Words: prostate cancer; radioimmunoimaging; EGP-1; PET; SPECT

J Nucl Med 2011; 52:1601-1607

DOI: 10.2967/jnumed.110.086520

\footnotetext{
Received Dec. 14, 2010; revision accepted Jun. 22, 2011.

For correspondence or reprints contact: Catharina M. van Rij, Department of Pharmacy, Route 864, Radboud University Nijmegen Medical Center, P.O. Box 9101, 6500 HB Nijmegen, The Netherlands.

E-mail: k.vanrij@akf.umcn.nl

Published online Aug. 24, 2011.

COPYRIGHT ๑ 2011 by the Society of Nuclear Medicine, Inc.
}

D espite ongoing improvement in both detection and treatment of prostate cancer, it is the second leading cause of cancer-related deaths in men in the Western world. Prostate cancer causes significant morbidity, especially when metastasized. Although treatable in early, hormone-dependent stages, prostate cancer can be managed only palliatively in the later, hormone-refractory phase of the disease.

At diagnosis, imaging of prostate cancer aims at differentiating between malignant and nonmalignant tissue. Diagnosis is usually performed effectively with imaging modalities such as transrectal ultrasound combined with biopsies or MRI, which are usually able to adequately detect and localize primary prostate cancer (1). In advanced prostate cancer, however, it is essential to differentiate between metastatic and nonmetastatic disease, to predict disease outcome, and to determine treatment options. Transrectal ultrasound and conventional MRI are less effective in detecting metastatic spread.

PET is a useful imaging modality to detect metastatic disease in several cancers. ${ }^{18}$ F-FDG PET is not suitable for staging patients with prostate cancer, since sensitivity is low because of poor ${ }^{18} \mathrm{~F}-\mathrm{FDG}$ uptake in most well-differentiated prostate cancer lesions and because of elimination of ${ }^{18} \mathrm{~F}$-FDG via the kidneys and urinary bladder $(2,3) .{ }^{18} \mathrm{~F}$ fluorocholine has been investigated extensively but also has a low sensitivity for detecting prostate cancer metastases $(2,3) .{ }^{11} \mathrm{C}$-acetate is a promising radiotracer for prostate cancer but requires an on-site cyclotron (1-3).

Several radiolabeled monoclonal antibodies (mAbs) have been developed and tested for prostate cancer imaging. An anti-prostate-specific membrane antigen $\mathrm{mAb},{ }^{111} \mathrm{In}$-capromab pendetide (ProstaScint; EUSA Pharma), has been approved for presurgical staging and evaluation of recurrence after focal therapy of prostate cancer but has several limitations. These include suboptimal visualization of bone metastases and the inability to discern viable from nonviable cancer cells, most likely because this mAb is directed against an intracellular epitope (3). However, the use of 
${ }^{111}$ In-capromab pendetide in combination with SPECT/CT showed improved results (4). J591, a humanized antiprostate-specific membrane antigen $\mathrm{mAb}$, has been reported to have better characteristics to detect bone metastases (3).

hRS7 is a humanized IgG1 mAb directed against the epithelial glycoprotein-1 (EGP-1; also known as TROP2). EGP-1 is a transmembrane glycoprotein with a molecular mass of approximately $46 \mathrm{kDa}$ (5). hRS7 was originally raised against human non-small cell carcinoma of the lung (6) and was found to be reactive with carcinomas of the lung, bladder, breast, cervix, ovary, stomach, and prostate. Most normal human tissues do not express EGP-1, including lymph nodes, heart, connective tissues, blood vessels, stomach, jejunum, and duodenum, but it is found at low levels in several normal glandular cells, including glands in the bronchus, breast, prostate, and skin and ducts and acini of the pancreas (6). Given its expression in prostate cancer, we studied the potential targeting ability of hRS7 IgG in a nude mouse-human prostate cancer model, examining the $\mathrm{mAb}$ radiolabeled with radioiodine or radiometals and applying SPECT and PET modalities.

\section{MATERIALS AND METHODS}

\section{The mAb hRS7}

The production and characterization of hRS7 (the humanized version of the murine mAb RS7-3G11) have been described previously (7). As a control mAb, a humanized anti-CD22 mAb, hLL2 (not reactive with prostate cancer), was used. Both antibodies were supplied by Immunomedics, Inc.

\section{Cell Culture}

The human prostate cancer cell line PC3 is an androgenindependent cell line, originally derived from a prostate cancer bone metastasis. Cells were obtained from American Type Culture Collection (CRL-1435) and grown in complete RPMI 1640 medium, supplemented with $10 \%$ fetal calf serum (Life Technologies). Before inoculation of mice to induce PC3 xenografts, tumor cells were washed with $0.9 \% \mathrm{NaCl}$, disaggregated with trypsin, and resuspended in 67\% complete RPMI 1640 medium with 33\% Matrigel (BD Biosciences) to the appropriate concentration $\left(3 \times 10^{6}\right.$ cells $\left./ 200 \mu \mathrm{L}\right)$.

\section{Murine Models}

Nude mice (Central Animal Facility, Radboud University Nijmegen Medical Center), 8-9 wk old, were adapted to laboratory conditions for at least $1 \mathrm{wk}$ before experimental use. They were housed under nonsterile standard conditions in filter-topped cages (5 mice per cage), with free access to animal chow (Sniff Voer) and water.

Male $\mathrm{BALB} / c$ nude mice were inoculated subcutaneously in the shoulder with $3 \times 10^{6} \mathrm{PC} 3$ cells suspended in $200 \mu \mathrm{L}$ of $67 \%$ complete RPMI 1640 medium with 33\% Matrigel. The subcutaneous PC 3 tumors grew to approximately $0.1 \mathrm{~g}$ in $10 \mathrm{~d}$ after tumor cell inoculation as determined by caliper measurements in 3 dimensions using the formula $\mathrm{V}=4 / 3 \pi$ (length $/ 2 \times$ width $/ 2 \times$ height/2), assuming that the density of tumor tissue is $1 \mathrm{~g} / \mathrm{cm}^{3}$. For an orthotopic mouse model, NMRI-foxn1 nude mice (Charles River) were used, because their prostate is larger and allows injec- tion of $20 \mu \mathrm{L}$ of cell suspension. NMRI-foxn1 mice were anesthetized and the abdomen was opened via a $1-\mathrm{cm}$ midline minilaparotomy. The prostate was gently lifted out of the abdomen and placed on gauze. Using a 29-gauge needle and a 1-mL syringe, 20 $\mu \mathrm{L}$ of a cell suspension containing $2 \times 10^{6} \mathrm{PC} 3$ cells in Matrigel was injected into one of the dorsal lobes of the prostate. After $7-$ $21 \mathrm{~d}$, palpable tumors developed in the prostate.

All experiments were approved by the national Animal Welfare Committee through the institutional Animal Welfare Committee of the Radboud University Nijmegen Medical Center and were conducted in accordance with the principles set forth by the Revised Dutch Act on Animal Experimentation.

\section{Radiolabeling of hRS7}

mAb hRS7 was radioiodinated according to the IODO-GEN method (8). Ten microliters of $0.5 \mathrm{M}$ phosphate buffer, $\mathrm{pH} 7.4 ; 86$ $\mu \mathrm{L}$ of $50 \mathrm{mM}$ phosphate buffer, $\mathrm{pH} 7.4 ; 3.5 \mu \mathrm{L}$ of hRS7 $(5.8 \mathrm{mg} /$ $\mathrm{mL}$ ); and $3.7 \mathrm{MBq}$ of $\mathrm{Na}^{125}$ (GE Healthcare Europe) were added to an Eppendorf vial coated with $50 \mu \mathrm{g}$ of IODO-GEN $(1,3,4,6-$ tetrachloro-3,6-diphenylglycoluril; Pierce Biotechnology, Inc.). The mixture was incubated for $10 \mathrm{~min}$ at room temperature, immediately followed by purification on a PD-10 column (GE Healthcare) eluted with phosphate-buffered saline (PBS), 0.5\% bovine serum albumin.

Conjugation of hRS7 with $p$-isothiocyanatobenzyl-diethylenetriaminepentaacetic acid (DTPA) (Macrocyclics) was done essentially as described by Ruegg et al. (9). Briefly, $0.5 \mathrm{~mL}$ of $\mathrm{mAb}$ hRS7 $(10 \mathrm{mg} / \mathrm{mL})$ was mixed with $50 \mu \mathrm{L}$ of $1.0 \mathrm{M} \mathrm{NaHCO}_{3}, \mathrm{pH}$ 9.5, and a 50-fold molar excess of $p$-isothiocyanatobenzyl-DTPA $(1.1 \mathrm{mg})$. After incubation at room temperature for $1 \mathrm{~h}$, the reaction mixture was dialyzed for $3 \mathrm{~d}$ in a Slide-A-Lyzer (20-kDa cutoff; Pierce) against $0.25 \mathrm{M} \mathrm{NH}_{4} \mathrm{Ac}, \mathrm{pH}$ 5.4. Determination of the substitution ratio, as described by Hnatowich et al. (10), revealed that 2 DTPA chelates were conjugated per hRS7 mAb molecule. Subsequently, the hRS7-DTPA conjugate was diluted in $0.25 \mathrm{M} \mathrm{NH}_{4} \mathrm{Ac}, \mathrm{pH} 5.4$, to $1 \mathrm{mg} / \mathrm{mL}$, and aliquots were stored at $-20^{\circ} \mathrm{C}$. hRS7-DTPA was labeled with ${ }^{111} \mathrm{InCl}_{3}$ by adding a 0.37 $\mathrm{MBq} / \mu \mathrm{g}$ concentration of hRS7-DTPA in $0.25 \mathrm{M} \mathrm{NH}_{4} \mathrm{Ac}$, $\mathrm{pH}$ 5.4. The mixture was incubated at room temperature for $30 \mathrm{~min}$. The radiolabeled hRS7 preparation was purified by gel filtration on a PD-10 column. The radiochemical purity was determined by instant thin-layer chromatography using $0.1 \mathrm{M}$ sodium citrate, $\mathrm{pH} 6$, as the mobile phase.

hRS7 was conjugated with desferrioxamine (Novartis) via an amide linkage and labeled with ${ }^{89} \mathrm{Zr}$ as described previously (11). The mAb and $\mathrm{N}$-succinyldesferrioxamine-tetrafluorphenol (VU Medical Center) were conjugated at room temperature for $30 \mathrm{~min}$. On average, 1 desferrioxamine-chelate per mAb molecule was conjugated. After conjugation, the $\mathrm{pH}$ was adjusted to 4.4 by adding $4 \mu \mathrm{L}$ of $0.25 \mathrm{M} \mathrm{H}_{2} \mathrm{SO}_{4}$ and the iron was removed from the chelator by adding $50 \mu \mathrm{L}$ of a $25 \mathrm{mg} / \mathrm{mL}$ solution of ethylenediaminetetraacetic acid and incubating for $30 \mathrm{~min}$ at $35^{\circ} \mathrm{C}$. The hRS7-desferrioxamine conjugate was purified on a PD-10 column that was eluted with a $5 \mathrm{mg} / \mathrm{mL}$ solution of gentisic acid in $0.9 \%$ $\mathrm{NaCl}, \mathrm{pH}$ 5. hRS7-desferrioxamine was radiolabeled using 120 MBq of ${ }^{89} \mathrm{Zr}$ oxalate (IBA Molecular). The $\mathrm{pH}$ of the ${ }^{89} \mathrm{Zr}$ oxalate solution was adjusted to 4.1 using a $2.0 \mathrm{M} \mathrm{Na}_{2} \mathrm{CO}_{3}$ solution. After $3 \mathrm{~min}$, the $\mathrm{pH}$ of the ${ }^{89} \mathrm{Zr}$ oxalate solution was adjusted to 6.9 using a $0.5 \mathrm{M} N$-(2-hydroxyethyl)piperazine- $N^{\prime}$-(2-ethanesulfonic acid) solution, and the purified hRS7-desferrioxamine was added. The solution was incubated for $90 \mathrm{~min}$ at $37^{\circ} \mathrm{C}$. Labeling efficiency 
was $60 \%$, as determined by instant thin-layer chromatography. The radiolabeled hRS7 preparation was purified by gel filtration on a PD-10 column, and the radiochemical purity $(>95 \%)$ was determined by instant thin-layer chromatography using $20 \mathrm{mM}$ citrate buffer, $\mathrm{pH}$ 6, as the mobile phase. Labeling efficiency varied considerably $(15 \%-80 \%)$, depending on the batch of ${ }^{89} \mathrm{Zr}$ oxalate used. The desired amount of ${ }^{89} \mathrm{Zr}$-hRS7-desferal $(20 \mu \mathrm{g}$ of hRS7-desferrioxamine labeled with $11 \mathrm{MBq}$ of ${ }^{89} \mathrm{Zr}$ ) was diluted in gentisic acid, $5 \mathrm{mg} / \mathrm{mL}, \mathrm{pH} 5$, to a volume of $200 \mu \mathrm{L}$. The control $\mathrm{mAb}$ hLL2, an anti-CD22 mAb, was conjugated with desferrioxamine and labeled with ${ }^{89} \mathrm{Zr}$ as described above.

\section{Immunoreactivity}

The immunoreactive fraction of the radiolabeled hRS7 was determined using freshly trypsinized PC 3 cells, as described by Lindmo et al. (12), with minor modifications. Briefly, a fixed amount of radiolabeled $\mathrm{mAb}(200 \mathrm{~Bq})$ was incubated with increasing concentrations of PC3 tumor cells in $0.5 \mathrm{~mL}$ of binding buffer (RPMI 1640 medium, $0.5 \%$ bovine serum albumin). A duplicate of the lowest cell concentration was incubated in the presence of an excess of unlabeled $\mathrm{mAb}$ to correct for nonspecific binding. After $1 \mathrm{~h}$ at $37^{\circ} \mathrm{C}$, the activity in the total vial was determined in a $\gamma$-counter (Wallac Wizard 3" 1480 automatic $\gamma$-counter). Cells were spun down and washed once with $500 \mu \mathrm{L}$ of binding buffer, and the activity in the cell pellet was determined in the $\gamma$-counter. The immunoreactive fractions of all radiolabeled preparations used in the experiments exceeded $80 \%$.

\section{Immunohistochemical Studies}

Frozen 5- $\mu \mathrm{m}$ sections of PC3 tumor xenografts were air-dried and fixed in cold acetone for $10 \mathrm{~min}$. After fixation, the slides were dried overnight and incubated with hRS7 $(4 \mu \mathrm{g} / \mathrm{mL})$ in PBS, $1 \%$ bovine serum albumin, for $1 \mathrm{~h}$ at room temperature. Slides were rinsed with PBS and were incubated with rabbit-antihuman-IgGperoxidase (DAKO) in PBS, $1 \%$ bovine serum albumin (preincubated in $10 \%$ normal mouse serum) for $30 \mathrm{~min}$. After being washed with PBS, the sections were stained with 3,3'-diaminobenzidine (Powervision DAB; Immunologic). All slides were counterstained with Mayer hematoxylin (Fluka Chemie) and mounted in Permount (Fisher Scientific). Human tumor sections were stained similarly except that these sections were incubated with the murine RS7 mAb, and rabbit-antimouse-IgG-peroxidase was used as the second mAb. Tissue samples were collected according to national and institutional guidelines.

\section{Biodistribution Studies}

The effect of the mAb dose on the biodistribution of ${ }^{111} \mathrm{In}-\mathrm{hRS} 7$ in mice with subcutaneous PC3 tumors was determined in groups of 5 mice that received escalating protein doses of ${ }^{111} \mathrm{In}$-hRS7 $(0.1,1,10,30$, and $100 \mu \mathrm{g}$ of hRS7 per mouse, $0.4 \mathrm{MBq})$. Three days after injection of the radiolabeled $\mathrm{mAb}$, mice were euthanized by $\mathrm{CO}_{2} / \mathrm{O}_{2}$ asphyxiation and a blood sample was obtained by heart puncture. Tissues (tumor, muscle, femur, lung, spleen, kidney, liver, duodenum, and colon) were dissected and weighed, and the radioactivity content was determined in a $\gamma$-counter (Wizard 3" 1480 automatic $\gamma$-counter). To permit calculation of the radioactive uptake in each organ as a fraction of the injected dose, an aliquot of the injection dose was counted simultaneously.

In another study, ${ }^{111} \mathrm{In}-\mathrm{hRS} 7(0.4 \mathrm{MBq}, 5 \mu \mathrm{g})$ and ${ }^{125} \mathrm{I}$-hRS7 (0.2 MBq, $5 \mu \mathrm{g}$ of hRS7) were coinjected in groups of 5 mice that were killed by $\mathrm{CO}_{2}$ asphyxiation and dissected at $3 \mathrm{~d}$ after injection. Tissue samples were counted in a $\gamma$-counter for ${ }^{111} \mathrm{In}$ and ${ }^{125}$ I activity. ${ }^{125}$ I activity was corrected for crossover with ${ }^{111}$ In activity. To check the accuracy of the ${ }^{125}$ I activity in the samples, samples were counted again 1 mo later. Results of the biodistribution experiments were expressed as percentage injected dose per gram of tissue (\%ID/g).

\section{Immuno-PET and Immuno-SPECT}

Groups of 5 mice with subcutaneous PC3 tumors were injected with $11 \mathrm{MBq}(20 \mu \mathrm{g})$ of ${ }^{89} \mathrm{Zr}$-hRS7. Although optimal protein dose was established at no more than $10 \mu \mathrm{g}$ of hRS7, a higher amount was chosen because of the higher activity that is needed for imaging. At 1, 3, or $7 \mathrm{~d}$ after injection, mice underwent immunoPET using a small-animal PET/CT scanner (Inveon; Preclinical Solutions, Siemens Healthcare Molecular Imaging) while anesthetized with a mixture of isoflurane, $\mathrm{N}_{2} \mathrm{O}$, and oxygen. One additional group was coinjected with an excess of $500 \mu \mathrm{g}$ of unlabeled hRS7, and 1 group received ${ }^{89} \mathrm{Zr}$-labeled hLL2 $(20 \mu \mathrm{g}, 6 \mathrm{MBq})$ to determine the nonspecific uptake in the tissues. Animals were placed supine in the PET/CT scanner. Emission scans were acquired over 15 (day 1), 20 (day 3), or $30 \mathrm{~min}$ (day 7), followed by a CT scan for anatomic reference (spatial resolution, $113 \mu \mathrm{m} ; 80 \mathrm{kV} ; 500 \mu \mathrm{A}$ ). Scans were reconstructed using Inveon Acquisition Workplace software, version 1.2, with an ordered-set expectation maximization 3dimensional maximum a posteriori algorithm having the following parameters: matrix, $256 \times 256 \times 159$; pixel size, $0.43 \times 0.43 \times 0.8$ $\mathrm{mm}$; and $\beta$-value, 0.1 . Images were analyzed quantitatively by the drawing of regions of interest, and tumor-to-liver ratios were calculated. After imaging, the mice were killed by $\mathrm{CO}_{2}$ asphyxiation and dissected to determine tissue uptake by $\gamma$-counting.

Orthotopically implanted mice were scanned using a U-SPECT II small-animal SPECT scanner (MILabs). All mice were injected with ${ }^{111}$ In-hRS7 $(37 \mathrm{MBq}, 10 \mu \mathrm{g}) 3 \mathrm{~d}$ before the SPECT images were acquired. Four groups of 5 mice were imaged at 10, 13, 17, and $24 \mathrm{~d}$ after intraprostatic PC 3 cell inoculation. A control group of 3 mice without surgery and without PC3 tumor was imaged simultaneously. The second control group of mice with PC3 tumors received $500 \mu \mathrm{g}$ of unlabeled hRS7 along with the injection of ${ }^{111}$ In-hRS7 on day 17, to block specific uptake of the radiolabeled $\mathrm{mAb}$. Thirty minutes before scanning, the mice received $0.5 \mathrm{mg}$ of furosemide subcutaneously to promote voiding of the bladder. The mice were killed and scanned for $30 \mathrm{~min}$ using the 1.0-mm-diameter-pinhole collimator tube. After scanning, biodistribution of the ${ }^{111}$ In-label was determined as described above. Scans were reconstructed with MILabs reconstruction software, which uses an ordered-subset expectation maximization algorithm, with a voxel size of $0.375 \mathrm{~mm}$. Tumor-to-liver ratios were calculated with the PMOD software (version 3.15, PMOD Technologies Ltd.).

\section{Statistical Analysis}

Statistical analysis was performed using Prism, version 4.00 (GraphPad), and InStat, version 3.05 (GraphPad), for Windows (Microsoft). Differences in uptake of radiolabeled RS7 were tested for significance using the nonparametric Mann-Whitney test for 2 groups. A $P$ value below 0.05 was considered significant. For multiple comparisons, the Bonferroni adjustment was applied.

\section{RESULTS}

\section{Immunohistochemical Studies}

Figure 1 shows that EGP-1 was expressed heterogeneously throughout the PC3 tumor (A and B). EGP-1 expression was membranous and cytoplasmic. Immunohistochemical analy- 
A

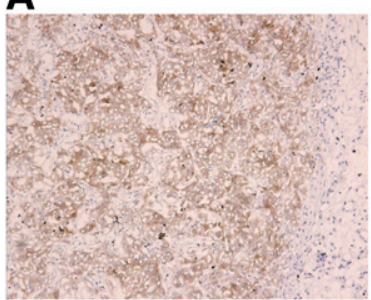

D

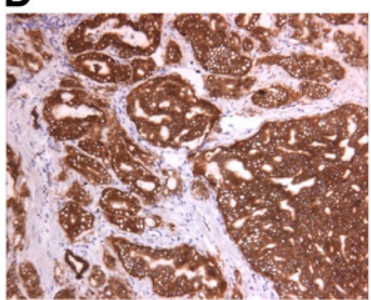

G

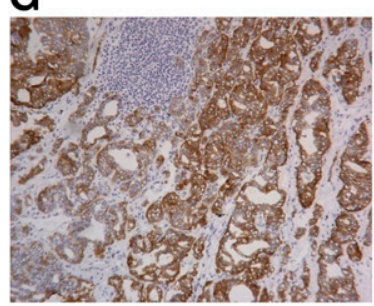

B

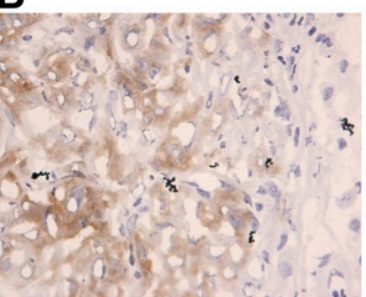

E

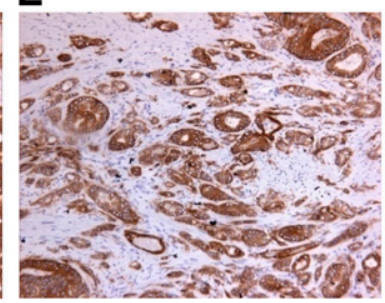

H

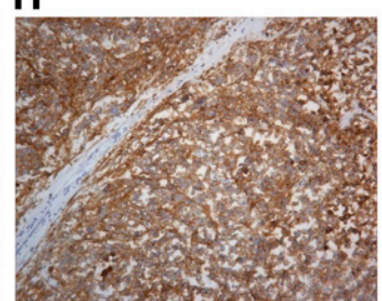

C

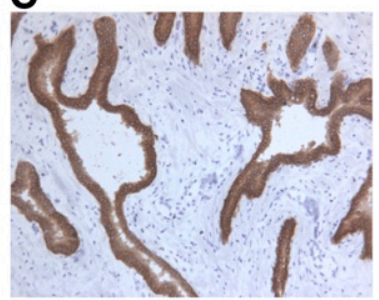

$\mathbf{F}$

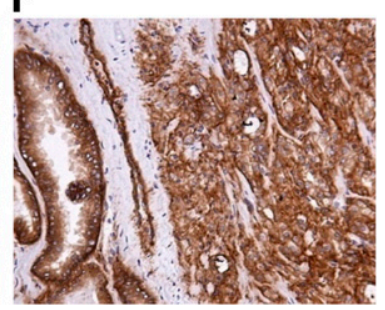

I

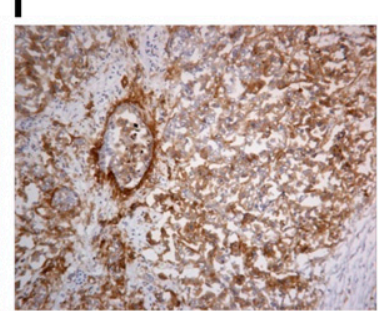

FIGURE 1. (A and $B)$ hRS7 staining of $P C 3$ mouse xenografts, magnified $\times 100(A)$ and $\times 400$ (B). (C-F) mRS7 staining of human prostate tissue with different Gleason scores: normal prostate (C), Gleason 6 (D), Gleason 7-8 (E), and Gleason 9-10 (F) $(\times 100)$. (G-I) mRS7 staining of 2 human lymph node metastases $(\mathrm{G}$ and $\mathrm{H})$ and 1 liver (I) metastasis $(\times 100)$.

sis of 3 human primary prostate tumors with varying Gleason scores showed high homogeneous and consistent expression of EGP-1 in all 3 prostate cancer tumors analyzed (D, E, and F). Normal human prostate (C) showed EGP-1 expression of the glandular epithelium. Immunohistochemistry also showed abundant expression of EGP-1 in prostate cancer metastases in a lymph node ( $\mathrm{G}$ and $\mathrm{H}$ ) and in the liver (I).

\section{Biodistribution Studies}

A protein dose study showed maximum tumor uptake $(>50 \% \mathrm{ID} / \mathrm{g})$ after injection of no more than $10 \mu \mathrm{g}$ of ${ }^{111} \mathrm{In}-\mathrm{hRS} 7$ at $3 \mathrm{~d}$ after injection (Fig. 2a). Tumor uptake of ${ }^{111}$ In-hRS7 decreased significantly with increasing doses of mAb from $60.8 \pm 14.8 \% \mathrm{ID} / \mathrm{g}$ at $0.1 \mu \mathrm{g} / \mathrm{mouse}$ to $22.2 \pm$ $7.1 \% \mathrm{ID} / \mathrm{g}$ at $100 \mu \mathrm{g} / \mathrm{mouse}(P=0.004)$. Protein dose did not affect concentrations in the blood or normal tissues. Tumor-to-blood ratios ranged from 3.0 (at $100 \mu \mathrm{g} / \mathrm{mouse}$ ) to 7.2 (at $0.1 \mu \mathrm{g} / \mathrm{mouse}$ ). Tumor weights were $0.08 \pm 0.043$ $\mathrm{g}$ and did not differ significantly between groups.

Figure 2B shows that uptake of ${ }^{111}$ In-hRS7 in tumor tissue at $3 \mathrm{~d}$ after injection was significantly higher than that of ${ }^{125} \mathrm{I}-\mathrm{hRS} 7(36.5 \pm 13.3 \% \mathrm{ID} / \mathrm{g}$ vs. $7.3 \pm 2.3 \% \mathrm{ID} / \mathrm{g}$, $P=0.0003$; weight of the tumors, $0.28 \pm 0.11 \mathrm{~g}$ ), yet normal tissue uptake was similar. This finding confirmed earlier studies with the murine RS7 mAb showing that residualizing radionuclides would be better retained with this internalizing mAb (13). The biodistribution of ${ }^{89} \mathrm{Zr}$ hRS7 was determined at 1, 3, and $7 \mathrm{~d}$ after injection. Figure 3 shows that tumor uptake of ${ }^{89} \mathrm{Zr}-\mathrm{hRS} 7$ at $3 \mathrm{~d}$ after injection was comparable to that of $10 \mathrm{mg}$ of ${ }^{111} \mathrm{In}-\mathrm{hRS} 7$ (46.7 \pm
$2.7 \%$ ID/g vs. $44.8 \pm 11.0 \% \mathrm{ID} / \mathrm{g})$. The same applies for the tissue uptake in all other organs ( $<9 \% \mathrm{ID} / \mathrm{g}$ for $\left.{ }^{89} \mathrm{Zr}-\mathrm{hRS} 7\right)$, except for femur uptake, which is significantly higher for ${ }^{89} \mathrm{Zr}-\mathrm{hRS} 7(6.9 \% \pm 0.9 \%$ vs. $1.0 \pm 0.2 \% \mathrm{ID} / \mathrm{g}, P<$ 0.0001). Tumor uptake increased significantly with time, from $30.1 \pm 2.8 \% \mathrm{ID} / \mathrm{g}$ at $1 \mathrm{~d}$ after injection to $54.3 \pm$ $7.0 \% \mathrm{ID} / \mathrm{g}$ at $7 \mathrm{~d}$ after injection; consequently, the tumorto-blood ratio increased with time to a ratio exceeding 8 at 7 $\mathrm{d}$ after injection $(P=0.0001)$. Tumor uptake was blocked by coinjection of an excess of unlabeled $\mathrm{mAb}$, resulting in nonspecific (non-antigen-mediated) tumor uptake of $11.2 \pm 0.8$ $\% \mathrm{ID} / \mathrm{g}$ at $3 \mathrm{~d}$ after injection. Tumor uptake of ${ }^{89} \mathrm{Zr}$-labeled control anti-CD22 $\mathrm{mAb}$ at $3 \mathrm{~d}$ after injection was low as well: $10.1 \pm 2.1 \% \mathrm{ID} / \mathrm{g}$.

Figure 4 shows that tumor uptake of ${ }^{111} \mathrm{In}-\mathrm{hRS} 7$ in the orthotopic mouse model at $3 \mathrm{~d}$ after injection was constant in the time investigated and on average was slightly lower than that detected in the subcutaneous model $(31.7 \pm 9.8 \%$ $\mathrm{ID} / \mathrm{g}$ at $10 \mathrm{~d}, 23.6 \pm 3.8 \% \mathrm{ID} / \mathrm{g}$ at $13 \mathrm{~d}, 32.0 \pm 12.9 \% \mathrm{ID} / \mathrm{g}$ at $17 \mathrm{~d}$, and $19.3 \pm 8.5 \% \mathrm{ID} / \mathrm{g}$ at $24 \mathrm{~d}$ after inoculation). Tissue uptake in all other organs was low $(<7 \%$ ID/g). Tumor uptake could be blocked by coinjection of an excess of unlabeled $\mathrm{mAb}$, resulting in nonspecific tumor uptake of $6.1 \pm 1.7 \% \mathrm{ID} / \mathrm{g}$. Mean weight of the tumors in this experiment was $0.042 \pm 0.026 \mathrm{~g}$; there was no significant tumor weight difference between the experimental groups.

\section{Immuno-PET/CT and Immuno-SPECT}

Small-animal PET/CT of ${ }^{89} \mathrm{Zr}$-hRS7 was performed on mice with subcutaneous PC3 tumors at 1,3 , and $7 \mathrm{~d}$ after 


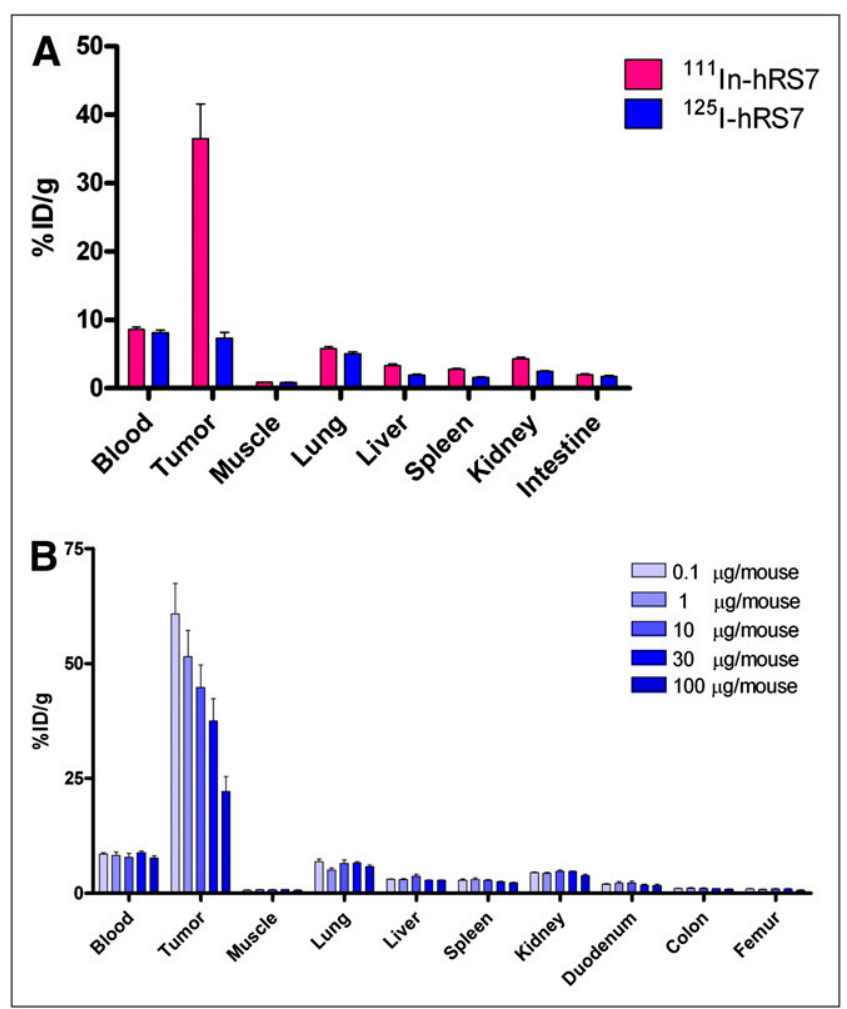

FIGURE 2. (A) Biodistribution of escalating ${ }^{111} \mathrm{In}-\mathrm{hRS} 7$ doses $(0.1-$ $100 \mu \mathrm{g}, 0.4 \mathrm{MBq}$ ) in BALB/c nude mice with subcutaneous PC3 xenograft at $3 \mathrm{~d}$ after injection $(n=5)$. (B) Biodistribution of ${ }^{125} \mathrm{I}-$ hRS7 (5 $\mu \mathrm{g}, 0.2 \mathrm{MBq})$ and ${ }^{111} \mathrm{In}-\mathrm{hRS} 7$ (5 $\mu \mathrm{g}, 0.4 \mathrm{MBq}$ ) in BALB/C nude mice with subcutaneous PC3 xenograft at $3 \mathrm{~d}$ after injection $(n=5)$.

injection. One day after injection of the radiolabeled $\mathrm{mAb}$, the PET/CT image showed high activity in blood. At $3 \mathrm{~d}$ after injection, blood levels were lower and the tumor was clearly visible. At $7 \mathrm{~d}$ after injection, ${ }^{89} \mathrm{Zr}$-hRS7 was retained in the tumor and had cleared from the rest of the body, with some activity in the skeleton (Fig. 5). PET/CT at $7 \mathrm{~d}$ after injection showed high uptake of the ${ }^{89} \mathrm{Zr}$-labeled hRS7 mAb in the PC3 tumor. There was no accumulation of radioactivity in the other organs, and there was some uptake in the skeleton (nose, the joints of the knees and shoulders, and the spine). Accumulation of ${ }^{89} \mathrm{Zr}$-hRS7 in the tumor was significantly reduced when an excess of unlabeled hRS7 was coinjected (Supplemental Fig. 5D). The same low uptake in the tumor was observed after injection of the ${ }^{89} \mathrm{Zr}$-labeled control mAb hLL2. Tumor-to-liver ratios were determined by ROI analysis at each time point: the tumor-to-liver ratio was $2.9 \pm 0.2,6.5 \pm 0.6$, and $7.7 \pm 1.3$ at 1,3 , and $7 \mathrm{~d}$ after injection, respectively. The tumor-to-liver ratio increased significantly between 1 and $3 \mathrm{~d}$ after injection $(P<0.0001)$.

Micro-SPECT imaging of ${ }^{111}$ In-hRS7 was performed in mice at $10,13,17$, and $24 \mathrm{~d}$ after inoculation of tumor cells in the prostate. Representative coronal sections through the center of the tumor are displayed in Figure 6. The mice in the control group without PC3 tumors showed no uptake of ${ }^{111}$ In-hRS7. Uptake in PC3 tumors in the prostate could be blocked by coinjection of an excess of unlabeled hRS7. Tumors were clearly visualized in the prostate in all mice. There was no visual difference in SPECT images acquired $10,13,17$, or $24 \mathrm{~d}$ after tumor cell inoculation. Tumor-toliver ratios were determined by region-of-interest analysis at each time point. The tumor-to-liver ratio was $6.9 \pm 0.3$ at $10 \mathrm{~d}$ after inoculation, $4.4 \pm 0.6$ at $13 \mathrm{~d}, 7.3 \pm 3.8$ at $17 \mathrm{~d}$, and $7.5 \pm 3.5$ at $24 \mathrm{~d}$. There was no significant increase in tumor-to-liver ratio with time. Tumors weights were 0.047 $\pm 0.017 \mathrm{~g}$ at $10 \mathrm{~d}, 0.028 \pm 0.015 \mathrm{~g}$ at $13 \mathrm{~d}, 0.046 \pm 0.012 \mathrm{~g}$ at $17 \mathrm{~d}$, and $0.067 \pm 0.042 \mathrm{~g}$ at $24 \mathrm{~d}$ after intraprostatic cell injection, and there was no significant tumor weight difference between the experimental groups.

\section{DISCUSSION}

In the present study, the potential of hRS7 for radioimmunoimaging of prostate cancer was investigated. Immunohistochemical analysis showed that EGP-1 is expressed on the epithelial cells of the normal prostate and is abundantly expressed on human primary prostate tumors and human prostate cancer metastases, indicating that EGP-1 is a potential target for prostate cancer imaging. Expression of EGP-1 in normal prostate tissue does not necessarily disqualify the use of hRS7 for specific imaging of prostate cancer. First, in situations where distant metastases are being examined, EGP-1 expression in the normal prostate is irrelevant. Second, it has yet to be determined whether EGP-1 would be accessible to the mAb in the intact tissue architecture of the normal prostate, as has been described for other antibodies (14). Since EGP-1

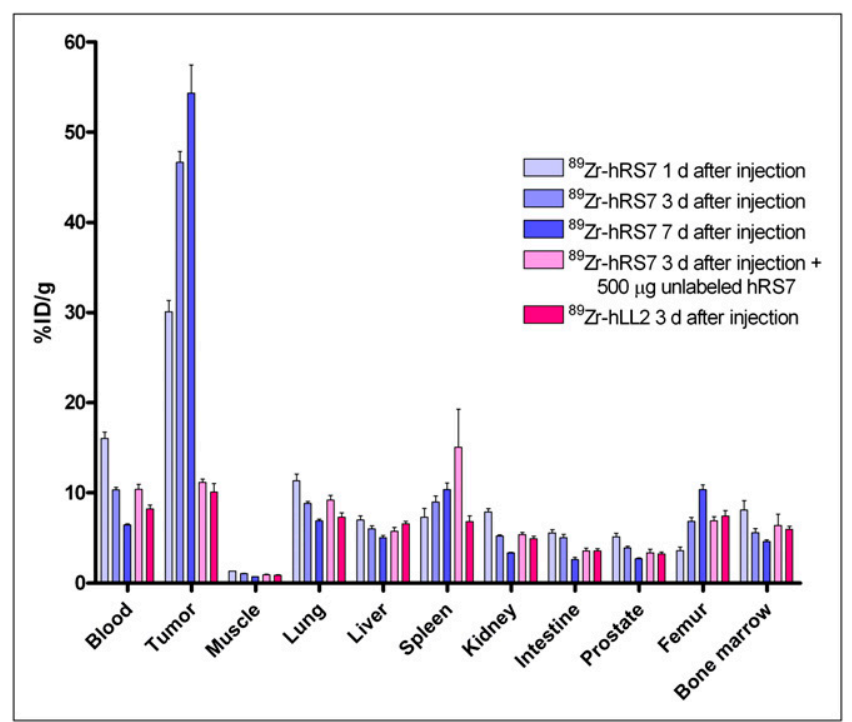

FIGURE 3. Biodistribution of ${ }^{89} \mathrm{Zr}-\mathrm{hRS} 7(20 \mu \mathrm{g}, 11 \mathrm{MBq})$ in BALB/ $c$ nude mice with subcutaneous PC3 xenograft at increasing time after injection (1, 3, and $7 \mathrm{~d}, n=5)$. One group of mice was coinjected with excess of $500 \mu \mathrm{g}$ of unlabeled hRS7, and 1 group received $20 \mu \mathrm{g}(6 \mathrm{MBq})$ of control mAb not reactive with prostate cancer ( ${ }^{89} \mathrm{Zr}$-hLL2). 


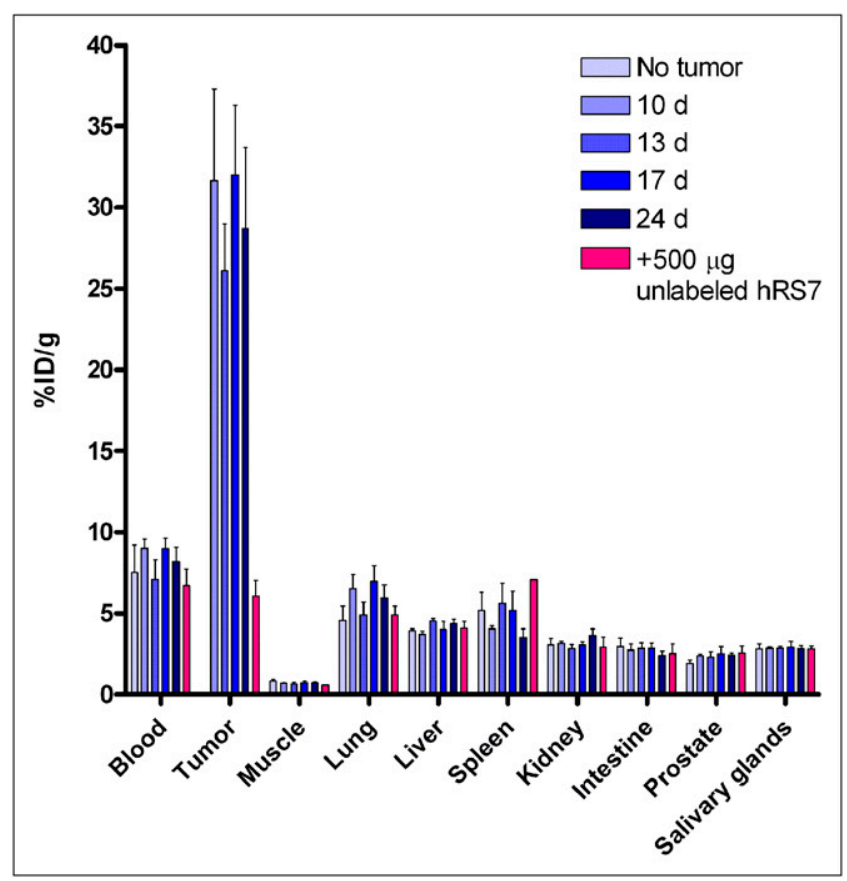

FIGURE 4. Biodistribution of ${ }^{111} \mathrm{In}-\mathrm{hRS} 7(10 \mu \mathrm{g}, 37 \mathrm{MBq})$ in NMRI nude mice with orthotopic PC3 xenograft at increasing time after cell inoculation $(10,13,17$, and $24 \mathrm{~d}, n=5)$. One group of mice without PC3 xenograft received same amount of ${ }^{111}$ In-hRS7. Second control group of mice with orthotopic PC3 tumor additionally received excess of $500 \mu \mathrm{g}$ of unlabeled hRS7 $(n=3)$.

is not expressed in the prostate of mice, we could not assess this issue.

The mAb protein dose escalation study with ${ }^{111}$ In-hRS7 revealed that the highest tumor uptake was obtained at no more than $10 \mu \mathrm{g}$, with progressively less uptake as the dose was increased to $100 \mu \mathrm{g}$. This likely reflects a gradual saturation of antigen. The antigen was not fully saturated at the $100-\mu \mathrm{g}$ dose, because when a $500-\mu \mathrm{g}$ blocking dose was administered, tumor uptake was as low as $10 \% \mathrm{ID} / \mathrm{g}$
A

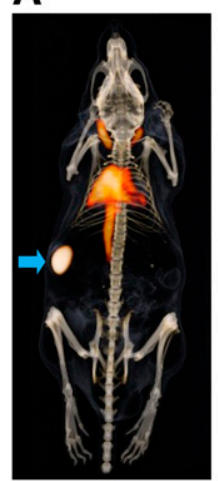

B

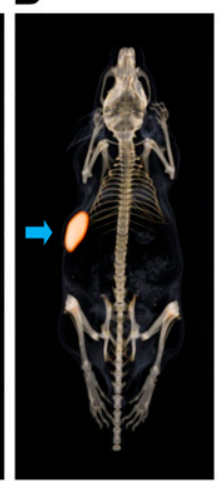

C

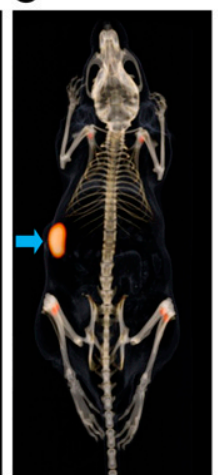

D

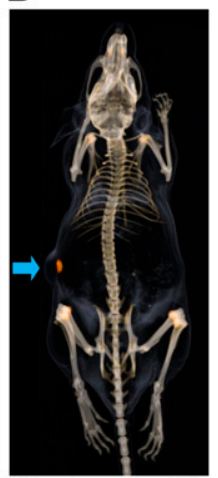

FIGURE 5. Anterior 3-dimensional volume-rendered projections of $\mathrm{PET} / \mathrm{CT}$ scans of mice with subcutaneous PC3 tumor on shoulder injected with ${ }^{89} \mathrm{Zr}$-hRS7 (20 $\left.\mu \mathrm{g}, 11 \mathrm{MBq}\right)$ acquired $1(\mathrm{~A}), 3$ (B and D), or 7 (C) days after injection. Control group (D) received same dose of $\mathrm{mAb}$ not reactive with prostate cancer ( ${ }^{89} \mathrm{Zr}$-hLL2, $\left.20 \mu \mathrm{g}, 6 \mathrm{MBq}\right)$. Arrows indicate tumor.
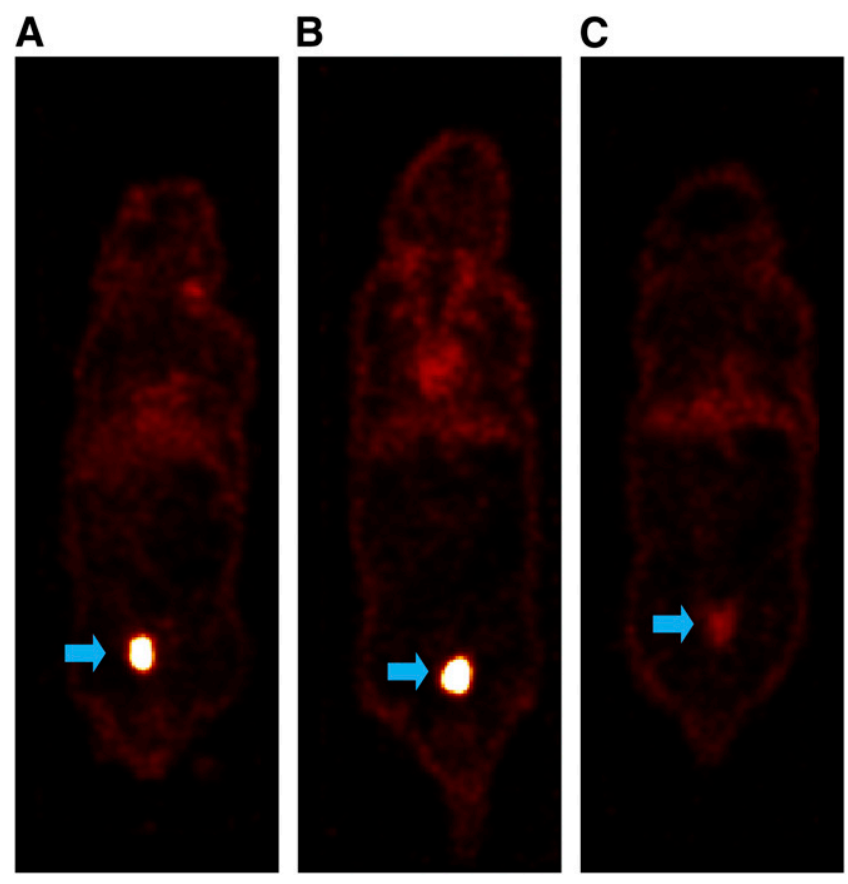

FIGURE 6. Anterior projections of SPECT scans of NMRI nude mice with orthotopic PC3 tumor in prostate injected with ${ }^{111} \mathrm{In}$ hRS7 $(10 \mu \mathrm{g}, 37 \mathrm{MBq})$ at $10(\mathrm{~A})$ and $24(\mathrm{~B})$ days after tumor cell inoculation. Control group of mice with orthotopic PC3 tumor was coinjected with excess of $500 \mu \mathrm{g}$ of unlabeled hRS7 (C). Arrows indicate tumor. Scans were acquired $3 \mathrm{~d}$ after injection.

(vs. $20 \% \mathrm{ID} / \mathrm{g}$ at $100 \mu \mathrm{g}$ ). Uptake in normal tissue was low $(<6 \%)$, as expected, because murine tissues do not express cross-reactive antigen and were not affected by the protein dose.

Simultaneous injection of ${ }^{111} \mathrm{In}-\mathrm{hRS} 7$ and ${ }^{125} \mathrm{I}-\mathrm{hRS} 7$ showed a much higher tumor uptake of ${ }^{111}$ In-hRS7 than of the ${ }^{125}$ I-labeled $\mathrm{mAb}(36.5 \pm 13.3 \% \mathrm{ID} / \mathrm{g}$ vs. $7.3 \pm$ $2.3 \% \mathrm{ID} / \mathrm{g}, P=0.0003)$. This is in agreement with previous reports that show murine RS7 internalization (15). Internalization causes catabolism of the labeled $\mathrm{mAb}$ in the lysosomes with subsequent washout of the ${ }^{125}$ I-labeled metabolite. On internalization, the ${ }^{111} \mathrm{In}$ - and ${ }^{89} \mathrm{Zr}$-labeled metabolites are retained intracellularly in the lysosomes. Uptake of ${ }^{111} \mathrm{In}$-hRS7 and ${ }^{125} \mathrm{I}$-hRS7 in normal tissues was relatively low (all $<6 \%$ ).

The biodistribution of ${ }^{89} \mathrm{Zr}$-hRS7 in mice with subcutaneous PC3 xenografts was similar to that of ${ }^{111} \mathrm{In}$-hRS7, except for femur uptake, which was significantly higher for the ${ }^{89} \mathrm{Zr}$-labeled hRS7. Tumor uptake increased significantly from 24 to $72 \mathrm{~h}$ after injection (from $26.6 \pm 7.9 \% \mathrm{ID} / \mathrm{g}$ to $43.6 \pm 11.5 \% \mathrm{ID} / \mathrm{g}, P=0.0003)$. Between 3 and $7 \mathrm{~d}$ after injection, tumor uptake stabilized $(54.3 \pm 7.0 \% \mathrm{ID} / \mathrm{g}$ at $7 \mathrm{~d}$ after injection), but because of the blood clearance of the radiolabeled $\mathrm{mAb}$, tumor-to-blood ratios increased from 2 at $24 \mathrm{~h}$ to more than 8 at $7 \mathrm{~d}$ after injection. Tumor uptake was specific, as blocking the EGP-1 antigens in vivo with an excess of unlabeled hRS7 resulted in a much lower uptake of the radiolabeled hRS7 $\mathrm{mAb}$ in the tumor $(11.2 \pm 0.8$ 
$\% \mathrm{ID} / \mathrm{g}, 3 \mathrm{~d}$ after injection). The same low nonspecific uptake $(10.1 \pm 2.1 \% \mathrm{ID} / \mathrm{g})$ was observed when ${ }^{89} \mathrm{Zr}$-hLL2 was injected. The specific accumulation of ${ }^{89} \mathrm{Zr}$-hRS7 could be clearly visualized with PET/CT. Some ${ }^{89} \mathrm{Zr}$ activity in the skeleton was observed, most likely because of incorporation of released ${ }^{89} \mathrm{Zr}$ from the internalized and catabolized $\mathrm{mAb}$ into the bone, as has been described for an ${ }^{89} \mathrm{Zr}$-anti-EGFR mAb (16). Region-of-interest analysis of the PET images revealed a significant increase of the tumor-to-liver ratio between 1 and $3 \mathrm{~d}$ after injection of ${ }^{89} \mathrm{Zr}$-hRS7 ( $2.9 \pm 0.2$ vs $6.5 \pm 0.6 \% \mathrm{ID} / \mathrm{g}$ ).

SPECT of PC3 tumors in the mouse prostate clearly visualized the intraprostatic tumors, with low background activity levels. Metastatic spread of the tumor was not observed. Both imaging and biodistribution results showed that uptake could be blocked by an excess of unlabeled mAb. A few mice showed accelerated $\mathrm{mAb}$ clearance from the blood, which occurs occasionally in BALB/c mice, as described previously (17). Tumor uptake in the intraprostatic tumors was slightly lower than that in the subcutaneous tumors and was not affected by time after tumor inoculation.

Previous studies with hRS7 have demonstrated high antigen expression on a wide range of human tumor types, including breast and lung tumors $(18,19)$. Our studies suggest that radiolabeled hRS7 may also be a useful agent for targeting prostate cancer. To further improve prostate cancer imaging, a pretargeting strategy with an EGP-1-targeted bispecific $\mathrm{mAb}$ would be desirable. Future experiments will be aimed at the use of this bispecific mAb.

\section{CONCLUSION}

hRS7 showed high and specific accumulation in PC3 xenografts in nude mice. Immunohistochemical staining of human prostate tumor samples disclosed abundant EGP-1 expression in primary prostate tumors and prostate cancer metastases. Biodistribution studies showed high and specific tumor uptake and high tumor-to-blood ratios, especially at later time points. These properties of hRS7 result in excellent immuno-PET and immuno-SPECT images of PC3 xenograft mouse models. hRS7 is a promising candidate for imaging of EGP-1-expressing prostate tumors.

\section{ACKNOWLEDGMENTS}

We thank Bianca Lemmers and Kitty Lemmens (Central Animal Facility, Radboud University Nijmegen Medical Center, The Netherlands) for their excellent technical assistance in the animal experiments, and Corrina de Ridder (Erasmus Medical Center Rotterdam, The Netherlands) for sharing her valuable expertise in setting up the orthotopic PC 3 mouse model. This study was performed within the framework of CTMM, the Center for Translational Molecular Medicine, PCMM project (grant 03O-203). David M. Goldenberg has financial interest in Immunomedics, Inc. No other potential conflict of interest relevant to this article was reported.

\section{REFERENCES}

1. Zaheer A, Cho SY, Pomper MG. New agents and techniques for imaging prostate cancer. J Nucl Med. 2009;50:1387-1390.

2. Beheshti M, Langsteger W, Fogelman I. Prostate cancer: role of SPECT and PET in imaging bone metastases. Semin Nucl Med. 2009;39:396-407.

3. Ravizzini G, Turkbey B, Kurdziel K, Choyke PL. New horizons in prostate cancer imaging. Eur J Radiol. 2009;70:212-226.

4. Sodee DB, Sodee AE, Bakale G. Synergistic value of single-photon emission computed tomography/computed tomography fusion to radioimmunoscintigraphic imaging of prostate cancer. Semin Nucl Med. 2007;37:17-28.

5. Basu A, Goldenberg DM, Stein R. The epithelial/carcinoma antigen EGP-1, recognized by monoclonal antibody RS7-3G11, is phosphorylated on serine 303. Int J Cancer. 1995;62:472-479.

6. Stein R, Basu A, Chen S, Shih LB, Goldenberg DM. Specificity and properties of MAb RS7-3G11 and the antigen defined by this pancarcinoma monoclonal antibody. Int J Cancer. 1993;55:938-946.

7. Stein R, Basu A, Goldenberg DM, Lloyd KO, Mattes MJ. Characterization of cluster 13: the epithelial/carcinoma antigen recognized by MAb RS7. Int J Cancer Suppl. 1994;8:98-102.

8. Fraker PJ, Speck JC Jr. Protein and cell membrane iodinations with a sparingly soluble chloroamide, 1,3,4,6-tetrachloro-3a,6a-diphrenylglycoluril. Biochem Biophys Res Commun. 1978;80:849-857.

9. Ruegg CL, Anderson-Berg WT, Brechbiel MW, Mirzadeh S, Gansow OA, Strand M. Improved in vivo stability and tumor targeting of bismuth-labeled antibody. Cancer Res. 1990;50:4221-4226.

10. Hnatowich DJ, Childs RL, Lanteigne D, Najafi A. The preparation of DTPAcoupled antibodies radiolabeled with metallic radionuclides: an improved method. J Immunol Methods. 1983;65:147-157.

11. Verel I, Visser GW, Boellaard R, Stigter-van WM, Snow GB, van Dongen GA. ${ }^{89} \mathrm{Zr}$ immuno-PET: comprehensive procedures for the production of ${ }^{89} \mathrm{Zr}$-labeled monoclonal antibodies. J Nucl Med. 2003;44:1271-1281.

12. Lindmo T, Boven E, Cuttitta F, Fedorko J, Bunn PA Jr. Determination of the immunoreactive fraction of radiolabeled monoclonal antibodies by linear extrapolation to binding at infinite antigen excess. J Immunol Methods. 1984;72: 77-89.

13. Stein R, Govindan SV, Mattes MJ, et al. Improved iodine radiolabels for monoclonal antibody therapy. Cancer Res. 2003;63:111-118.

14. Hilgers J, Zotter S, Kenemans P. Polymorphic epithelial mucin and CA125bearing glycoprotein in basic and applied carcinoma research. Cancer Rev. 1989;11-12:3-10.

15. Shih LB, Xuan H, Aninipot R, Stein R, Goldenberg DM. In vitro and in vivo reactivity of an internalizing antibody, RS7, with human breast cancer. Cancer Res. 1995;55(suppl):5857s-5863s.

16. Perk LR, Visser GW, Vosjan MJ, et al. ${ }^{89} \mathrm{Zr}$ as a PET surrogate radioisotope for scouting biodistribution of the therapeutic radiometals ${ }^{90} \mathrm{Y}$ and ${ }^{177} \mathrm{Lu}$ in tumorbearing nude mice after coupling to the internalizing antibody cetuximab. $\mathrm{J} \mathrm{Nucl}$ Med. 2005;46:1898-1906.

17. Reddy N, Lin Ong G, Behr TM, Sharkey RM, Goldenberg DM, Mattes MJ. Rapid blood clearance of mouse IgG2a and human IgG1 in many nude and $\mathrm{nu} /+$ mouse strains is due to low IgG2a serum concentrations. Cancer Immunol Immunother. 1998;46:25-33.

18. Stein R, Chen S, Sharkey RM, Goldenberg DM. Murine monoclonal antibodies raised against human non-small cell carcinoma of the lung: specificity and tumor targeting. Cancer Res. 1990;50:1330-1336.

19. Stein R, Chen S, Haim S, Goldenberg DM. Advantage of yttrium-90-labeled over iodine-131-labeled monoclonal antibodies in the treatment of a human lung carcinoma xenograft. Cancer. 1997;80(suppl):2636-2641. 